\title{
Physical Caregiving and Stress- An examination of Mediating Role of Social Support to Caregivers of Pediatric Cancer Patients in Pakistan
}

\author{
Ansa Qurat-ul-ain \\ School of Applied Psychology, Social Work and Policy. \\ University Utara Malaysia \\ Prof. Najib Ahmed Marzuki (Corresponding author) \\ School of Applied Psychology, Social Work and Policy. \\ University Utara Malaysia
}

\begin{abstract}
Informal caregivers has always been a significant source of providing care to the individuals with chronic illness such as cancer. Diagnosis of cancer in children can have harmful effects on a psychosocial and emotional well-being of a caregiver. Considering the caregiver stress theory as a theoretical framework, the purpose of this research was to determine the relationship of physical caregiving to the children with cancer in relation to caregivers' stress taking social support as a mediator. The data was collected from 100 primary caregivers of children aged 0-19 years from hospitals of Pakistan using measurement scales of Caregiving task questionnaire, Medical Outcomes Study-Social Support Survey and Modified Caregiver Strain Index. For data analysis, descriptive statistics and multivariate analysis were conducted. Findings showed positive correlation of physical caregiving and social support with caregivers' stress as well as significant mediating effects of social support on caregivers' stress. This suggests that social support is a resource of mental health for caregivers of children with cancer highlighting the importance of social support while designing and implementing caregiver health interventions.
\end{abstract}

Keywords: Cancer children, primary caregivers, physical caregiving, social support, caregivers' stress

\section{INTRODUCTION}

"Cancer" refers to group of diseases described as the abandoned growth of abnormal cells affecting multiple parts of the body [1]. Worldwide, cancer has become an enormous global health burden [2] with more than half of the annual cancer cases occurring in Asia, Africa and Central and South America. According to surveys, childhood cancer is rare showing only one percent of total diagnosis of cancer with estimated 175,000 cancer cases diagnosed annually in children younger than 19 years of age. Although survival rate for childhood cancer has been increased by the advanced treatments, it is still the second leading cause of death in children and adolescents.

Over the years, cancer children have been considered to be affected by the disease but the diagnosis of cancer in children is a life changing event for caregivers as well [3]. Generally, these (Informal) caregivers are family members that can be a person of any age who is in the home, provides unusual, uncompensated care for months and years investing a great amount of time and energy by performing physical, emotional, social or financial demanding tasks [4] becoming the essential resource of care for ill family members. Caregiving includes; 
Instrumental Activities of Daily Living (IADLs) like cleaning and transportation and Activities of Daily Living (ADLs) such as eating and toileting. These constant physical and social demands of caregiver role influence the changes in psychological health of caregiver and social isolation [5]. Caregivers of cancer children face multiple stressors related to cancer including threat to their child's life, repeated hospitalizations, and alteration of roles and responsibilities [6].

Theories seeking to understand the adaptation of family to the chronic childhood diseases consider several variables such as caregiver role, caregivers' stress and social support, suggests the significance of these variables while coping with illness [7]. Stress, in this scenario, is a self-defeating situation that hinders efforts and defeat goals of the caregivers by causing fatigue [8]. Theoretical models of the caregiver stress process [8] indicates some mediators such as social support as a coping strategy. The concept of social support as a mediator against stress in difficult situations is not new. It refers to psychological resources that an individual believes to be available through his/her interpersonal relationships. It is hypothesized to protect mental health directly and indirectly as a buffer against stressful circumstances, while its absence leads to negative feelings leaving adverse effects on the caregivers $[9,10]$.

Previously, few of the studies are theory driven and literature has little to show about the effect of factors unique to cancer, such as its sudden onset, life-threatening nature, and the sporadic need of patient's care. This shows that cancer caregiving is relatively acute and intermittent requiring constant help. Literature has found that the unpredictability of the course of cancer and its recurrence are associated with the high emotional stress among caregivers of cancer $[11,12]$.

Particularly, in Pakistan, family members are the main source of caregiving at home because of the cultural expectations and a sense of obligation rather than out of personal interest to help [13] thus, becoming the second victim of disease, under sudden and extreme circumstances. These family caregivers may be at risk of developing mental health problems appraising their caregiving situation as stressful as the effects of stress on caregiver health also depend on the caregiving situation [14]. Number of studies $[11,15,16]$ have mentioned that social support can protect an individual under stress and helps to maintain good emotional experience [17]. Therefore, it is vital to understand the factors influencing the caregivers' strain in Pakistan since studies conducted in different regions of the world may not be applicable to caregivers of cancer patients in Pakistan due to social, economic and environmental differences.

Therefore, the objectives of this study are to examine the effects of physical caregiving on the caregivers' level of stress and to examine the direct and mediating role of social support on caregivers. One theoretical perspective that guided the analysis of caregiving experiences for this study is a traditional Stress Process Theory [8] for examining caregiving effects on caregivers' mental health. Using this perspective, researchers have shown that various caregiving demands, including IADLs as well as availability of social support in caregiving process are associated with poor psychological outcomes of caregivers [18]. Based on the aforementioned considerations of stress process theory, it has been hypothesized for this study that physical caregiving and social support would be significantly associated with stress ( $\mathrm{H} 1$ and $\mathrm{H} 2$ ) whereas social support as a mediator between physical caregiving and stress acts as a coping mechanism (H3). 


\section{Participants}

\section{METHOD}

The sample for this study comprised of 100 primary caregivers of children with cancer aged 019 years from the cancer hospitals in Pakistan. Simple random with cluster sampling was used in order to select the respondents from the hospitals.

\section{Instruments}

Caregiving Task Questionnaire (CTQ) by Wallhagen [19].This physical caregiving task scale consists of 12 questions regarding the act of providing physical care to the patient. It comprises of items to be answered on a 5-point Likert scale ranging from (1) strongly disagree to (5) strongly agree about the physical assistance provided by the caregiver to the care recipient. The maximum score indicates the high level of physical involvement of caregiver while caregiving. The value of Cronbach's Alpha was found to be 0.86 for this scale.

Medical Outcomes Study: Social Support Survey (MOS-SSS) by Sherbourne and Stewart [20]. This instrument assess the function of social support provided to the caregiver in stressful circumstances. There are 10 items with 5-point Likert scale ranging from (1) strongly disagree to (5) strongly agree. The high score indicates that the respondent receives maximum social support. The Cronbach's alpha of the scale was 0.97.

Modified Caregiving Strain Index (MCSI) by Thornton and Travis [21]. This instrument is used to assess the strain of caregivers providing long-term care to the close ones. The scale of this 10 item instrument is 3-point Likert scale ranging from (1) on a regular basis to (3) never. The high score indicates the higher level of caregiver stress. Cronbach's Alpha value was 0.90 for this scale.

\section{Data collection}

The present study was cross sectional and descriptive in nature, conducted in four cancer treatment hospitals in Pakistan. Initially, permission was taken from the Medical Superintendent of each of the selected hospitals to conduct the survey. Later, primary caregivers of children with cancer who were willing to participate in the study were consulted from each hospital and informed consent form was signed followed by the completion of the instruments selected for this study.

\section{Data analysis}

After raw data was collected, the questionnaires were keyed in to the Statistical Package for the Social Sciences (SPSS v23) software for statistical analysis of the instruments used in this study. The SmartPLS v3.0 was used for determining the outer model and the inner model by assessing reliability and validity of the scales and testing of hypotheses.

\section{RESULTS}

The response rate of the questionnaires was $100 \%$ with the $12.8 \%$ variance explained by the single factor. No missing value was found and for the normality test, the values of skewness and kurtosis were found within acceptable range of $<2$ to $<7$ respectively. The sample consists mostly of the female caregivers (65\%) where $78 \%$ of the respondents were parents of the children while the rest are siblings (15\%), grandparents (3\%) and other relatives (4\%). The mean age of the respondents was 32.6 years. About $81 \%$ of the caregivers were married while $19 \%$ of the caregivers were single or divorcee. The highest education level of the caregivers was Masters (28\%) while others were having varied education level such as primary (7\%), 
secondary (19\%), intermediate (15\%) and graduation (23\%). Maximum respondents (44\%) were having varied jobs other than government or private jobs. The duration of illness of children varied mostly from $0-3$ years (64\%) while $27 \%$ and $9 \%$ were cancer patients from $4-6$ years $(27 \%)$ and $7-10$ years (9\%) respectively.

For analysis of data in SmartPLS, all variables were taken as reflective and were treated as first order constructs. Firstly, the analysis of measurement model (outer model) ensured the validity and reliability of the constructs as shown in Table 1.

Table 1. Loadings, Reliability, Convergent Validity and Discriminant Validity Values

\begin{tabular}{|c|c|c|c|c|c|c|}
\hline Variables & Items & Loadings & Cronbach's Alpha & CR & AVE & Discriminant Validity \\
\hline \multirow[t]{10}{*}{ CS } & CS1 & 0.854 & \multirow[t]{10}{*}{0.938} & \multirow[t]{10}{*}{0.948} & \multirow[t]{10}{*}{0.645} & \multirow[t]{10}{*}{0.803} \\
\hline & CS10 & 0.789 & & & & \\
\hline & $\mathrm{CS} 2$ & 0.862 & & & & \\
\hline & CS3 & 0.854 & & & & \\
\hline & $\mathrm{CS} 4$ & 0.611 & & & & \\
\hline & CS5 & 0.801 & & & & \\
\hline & CS6 & 0.789 & & & & \\
\hline & CS7 & 0.821 & & & & \\
\hline & CS8 & 0.813 & & & & \\
\hline & CS9 & 0.811 & & & & \\
\hline \multirow[t]{11}{*}{ PC } & PC1 & 0.566 & \multirow[t]{11}{*}{0.907} & \multirow[t]{11}{*}{0.921} & \multirow[t]{11}{*}{0.519} & \multirow[t]{11}{*}{0.72} \\
\hline & PC10 & 0.731 & & & & \\
\hline & PC11 & 0.745 & & & & \\
\hline & PC12 & 0.791 & & & & \\
\hline & PC2 & 0.773 & & & & \\
\hline & PC3 & 0.814 & & & & \\
\hline & PC4 & 0.775 & & & & \\
\hline & PC6 & 0.543 & & & & \\
\hline & PC7 & 0.644 & & & & \\
\hline & PC8 & 0.715 & & & & \\
\hline & PC9 & 0.77 & & & & \\
\hline \multirow[t]{5}{*}{ SS } & SS10 & 0.834 & \multirow[t]{5}{*}{0.771} & \multirow[t]{5}{*}{0.846} & \multirow[t]{5}{*}{0.525} & \multirow[t]{5}{*}{0.724} \\
\hline & SS5 & 0.713 & & & & \\
\hline & SS6 & 0.686 & & & & \\
\hline & SS8 & 0.648 & & & & \\
\hline & SS9 & 0.726 & & & & \\
\hline
\end{tabular}

Note: CS=Caregiver Stress, PC=Physical Caregiving, SS=Social Support, CR=Composite Reliability, AVE=Average Variance Extracted

The results shows that internal consistency reliability is satisfactory for all constructs with CR of $0.94,0.92$ and 0.84 for caregiver stress, physical caregiving and social support respectively. Next, for the indicator reliability all the outer loadings met the minimum threshold value of 0.708 with few exceptions having lower value but with AVE $>0.5$. Additionally, discriminant validity is also acceptable between all the constructs with higher squared root values of AVE than other constructs. In terms of assessment of outer loadings, 6 items were deleted showing low indicator reliability to increase the AVE which is only $20 \%$ of the indicators in the model. 
For the assessment of structural model, first the collinearity was assessed $(\mathrm{PC}=1.97, \mathrm{SS}=1.97)$ indicating the absence of collinearity issue. Later, for the assessment of relevance and significance of the structural model, the PLS algorithm and bootstrapping was performed showing the values of path coefficient of all variables in Table 2.

Table 2. Results of Hypotheses Testing (Direct Relationships)

\begin{tabular}{cllllllll}
\hline Hypothesis & Relationship & $\begin{array}{l}\text { Std } \\
\text { Beta }\end{array}$ & $\begin{array}{l}\text { Std } \\
\text { Error }\end{array}$ & t-value & p-value & Decision & $\mathrm{R}^{2}$ & $\mathrm{f}^{2}$ \\
\hline H1 & PC -> CS & 0.228 & 0.100 & 2.286 & 0.023 & Supported & 0.601 & 0.068 \\
H2 & SS -> CS & 0.603 & 0.104 & 5.794 & 0.000 & Supported & 0.488 & 0.473 \\
\hline
\end{tabular}

In this study, 2 direct hypothesis were developed between the constructs. Based on the assessment of the path coefficient as shown in Table 2, both relationships are found to have tvalue $>1.645$, thus significant at 0.05 level of significance. The predictors of Physical caregiving $(\beta .22, \mathrm{p}<.05)$ and Social support $(\beta .60, \mathrm{p}<.01)$ are positively related to caregiver stress which explains $60 \%$ and $49.3 \%$ of variance in caregiver stress respectively. Therefore $\mathrm{H} 1$ and $\mathrm{H} 2$ are supported. The $\mathrm{R}^{2}$ value of 0.60 indicates a substantial model. Moreover, mediation took place with the bootstrapping procedure providing interval estimate of a population parameter.

Table 3. Results of Hypotheses Testing (Indirect/Mediating Relationships)

\begin{tabular}{cccccccc}
\hline Hypothesis & Relationship & $\begin{array}{l}\text { Std } \\
\text { Beta }\end{array}$ & Std Error & p-value & $5.00 \%$ & $95.00 \%$ & Decision \\
\hline H3 & PC > SS > CS & 0.424 & 0.074 & 0.000 & 0.269 & 0.560 & Supported \\
\hline
\end{tabular}

The results in Table 3. indicates that social support mediates the relationship between physical caregiving and caregiver stress $(\beta .70 ; \mathrm{p}<.05)$. This provides the result of H3 of this study. Next the effect size $\left(f^{2}\right)$ in Table 2 indicates that social support (0.47) has a large effect as compared to physical caregiving $(0.06)$ in producing the $\mathrm{R}^{2}$ for caregiver stress. The analysis revealed that physical caregiving and social support can leads to higher level of stress when examined directly whereas social supports acts as a mediator between physical caregiving and stress of caregiver.

\section{DISCUSSION}

Literature has suggested detrimental effects of caregiving to cancer children on stress of caregivers $[22,23]$. This study shows the extent to which caregivers' stress is influenced by the factors associated with stress. The caregivers' demographic characteristics suggests that most of the caregivers are married females in the middle age having an entire family setup to look after. Further, most respondents were having jobs with minimal pay implying that the need to care for a cancer child costs not only emotional and physical but also financial. Financial difficulties may prevent an individual to effectively integrate into a social environment and may restrict communication [10].

In support of the first hypothesis, findings indicate the positive relation of physical caregiving to caregivers' stress, showing the influence of physical caregiving on the stress of caregivers. There is much agreement in the literature regarding the relationship between the physical caregiving and the caregivers' stress [24, 25]. Previous studies [26, 27, 28] have found similar results and argue that the stress of caregiver is likely to depend on how the caregiver is ready to provide physical care. In case of this investigated sample, the above considerations requires more attention as high level of stress was exhibited by the respondents requiring clinical evaluation or therapy assistance. 
Taking stress as a risk factor for caregivers, literature has shown that social support behaved as a protective factor [17] indicating high percentage scores on the MOS-SSS. However, although the respondents reported satisfaction with the received social support, it did not seem sufficient to reduce the level of caregivers' stress. According to the findings of second hypothesis, higher level of social support increases the caregivers' stress level which indicates that the high scores on social support scale suggests that the respondents get support whenever they require. In literature, lack of association of caregivers' stress with social support is considered as an uncommon result $[15,16]$. This finding may be explained by considering the constructs of the instrument that investigates the availability of various types of support without considering the specific demands associated with caregiving. Nevertheless, the instrument provided relevant data for understanding caregivers' stress.

The third hypothesis, explains the presence of the mediating effect of social support between physical caregiving and caregivers' stress. Findings from previous studies are found to be consistent as few elements of social support are linked with positive outcomes of health [29, 30]. Voluminous studies [31, 32] have reported a stress-buffering effect of social support on mental health suggesting that the caregivers were contented with the types of support that they need while physically caring the cancer children. However, any other important type of social support may not have been sufficiently investigated and have provided different effect of social support on caregivers' stress.

\section{CONCLUSION}

The results of the present study showing positive relation of physical caregiving and social support with caregivers' stress and presence of mediating effect of social support are useful in developing strategies that can prevent and reduce the caregivers' stress as they show which investigated variable is more effective in developing caregivers' stress. Regarding the limitations of the study, it was not possible to include the optimal number of individuals due to the lack of knowledge of the population size while generalization of the results are cautioned.

Considering the findings of this study and assuming children as a vital part of a dynamic system, the future studies should find out the association of physical caregiving, social support and caregivers' stress in various settings.

\section{ACKNOWLEDGMENT}

This research was a non-funded research which is conducted in different hospitals of Punjab, Pakistan. We extend our gratitude to the hospital administration and the families who participated in this study.

\section{Competing Interests}

The authors have no competing interests to declare.

\section{References}

International Agency for Research on Cancer [IARC] (2016). Agents Classified by the IARC Monographs, 1, 114.

American Cancer Society. Global Cancer Facts \& Figures (2016). Atlanta: American Cancer Society. 
Litzelman, K., Catrine, K., Gangnon, R., \& Witt, W. P. (2011). Quality of life among parents of children with cancer or brain tumors: The impact of child characteristics and parental psychosocial factors. Quality of Life Research, 20, 1261-1269.

Abdelmoneium, A. O. and Alharahsheh, S. T. (2016). Family Home Caregivers for Old Persons in the Arab Region: Perceived Challenges and Policy Implications. Open Journal of Social Sciences, 4, 151-164.

Ugalde, A., Krishnasamy. M., \& Schofield, P. (2013). Development of an instrument to measure self-efficacy in caregivers of people with advanced cancer. Psycho-oncology, 22(6), 1428-1434.

Long, K. A., \& Marsland, A. L. (2011). Family adjustment to childhood cancer: A systematic review. Clinical Child and Family Psychology Review, 14, 57-88.

Carona, C., Crespo, C., \& Canavarro, M. C. (2013). Similarities amid the difference: Caregiving burden and adaptation outcomes in dyads of parents and their children with and without cerebral palsy. Research in Developmental Disabilities, 34(3), 882-893.

Pearlin, L., Mullan, J. T., Semple, S. J., \& Skaff, M. M. (1990). Caregiving and the stress process: An overview of concepts and their measures. Gerontologist, 30, 583-595

Whittingham, K., Wee, D., Sanders, M. R., \& Boyd, R. (2013). Predictors of psychological adjustment, experienced parenting burden and chronic sorrow symptoms in parents of children with cerebral palsy. Child: Care, Health and Development, 39(3), 366-373.

Panganiban-Corales and Medina. (2011). Family resources study: part 1: family resources, family function and caregiver strain in childhood cancer. Asia Pacific Family Medicine, 10, 14.

Soylu, C., Ozaslan, E., Karaca, H., \& Ozkan, M. (2015). Psychological distress and loneliness in caregiver of advanced oncological inpatients. Journal of Health Psychology, 1-11.

Bartolo, M., Luca, D. D., Serrao, M., Sinforiani, E., Zucchella, C., \& Sandrini, G. (2010). Caregiver burden and needs in community neuro-rehabilitation. Journal of Rehabilitation Medicine, 42, 818-822.

Yousafzai, A., Bhutto, N., Ahmar, S., Siddiqui, M., \& Selamat, S. (2011). Caregivers' stress of cancer patients in a tertiary care hospital. Journal of Postgraduate Medical Institute (Peshawar - Pakistan), 22(1), 62-65.

Asima, M. K., Rizwan, T., Arfeen, F., \& Farhana, K. (2015). Quality of life of caregivers and non-caregivers. Annals of Pakistan Institute of Medical. Sciences, 11(1), 35-39.

Casale, M., \& Wild, L. (2012). The relationship between social support and the health of HIV-positive caregivers of children: A review of the empirical literature, Vulnerable Children and Youth Studies: An International Interdisciplinary Journal for Research, Policy and Care, 7(3), 260-282.

Rafiyah, I., Suttharangsee, W., Sangchan, H. (2011). Social support and coping of Indonesian family caregivers caring for persons with schizophrenia. Nurse Media Journal of Nursing, 1(2), 159-169.

Maulik, P. K., Eaton, W. W., \& Bradshaw, C. (2011).The effect of social networks and social support on mental health services use, following a life event, among the Baltimore Epidemiologic Catchment Area cohort. Journal of Behavioral Health Services and Research, 38(1), 29-50.

Perkins, M., Howard, V.J., Wadley, V.G., Crowe, M., Safford, M.M., Haley, W.E., Howard, G., \& Roth, D.L. (2012). Caregiving strain and all-cause mortality: evidence from the Regards study. Journals of Gerontology Series B: Psychological Sciences and Social Sciences.

Wallhagen, M. I. (1990). Perceived control and adaptation in elderly caregivers. PhD Thesis.

Sherbourne, C. D., \& Stewart, A. L. (1991). The MOS social support survey. Social Science \& Medicine, 32(6), 705714.

Thornton, M., \& Travis, S. S. (2003). Analysis of the reliability of the Modified Caregiver Strain Index. The Journal of Gerontology, Series B, Psychological Sciences and Social Sciences, 58(2), 129.

Narayan, S. M., Varghese, M., Hepburn, K., Lewis, M., Paul, I., \& Bhimani, R. (2015). Caregiving experiences of family members of persons with dementia in South India. American Journal of Alzheimer's disease and other Dementias, 30(5), 508-516.

Bevans, M. F., \& Sternberg, E. M. (2012). Caregiving burden, stress, and health effects among family caregivers of adult cancer patients. Journal of the American Medical Association, 307(4), 398-403. 
Lund, L., Ross, L., Peterson, M. A., \& Groenvold, M. (2015). The interaction between informal cancer caregivers and health care professionals: a survey of caregivers' experiences of problems and unmet needs. Support Care Cancer, 23(6), 1719-1733.

Ellis, J. (2012). The impact of lung cancer on patients and carers. Chronic Respiratory Disease Journal, 9, 39-47.

Chambers, S. K., Girgis, A., Occhipinti, S., Hutchison, S., Turner, J., Morris, B., \& Dunn, J. (2012). Psychological distress and unmet supportive care needs in cancer patients and carers who contact cancer help lines. European Journal of Cancer Care, 21(2), 213-223.

Beattie, S., \& Lebel, S. (2011). The experience of caregivers of hematological cancer patients undergoing a hematopoietic stem cell transplant: a comprehensive literature review. Psycho-Oncology, 20(11), 1137-1150.

Okoye, U.O., \& Asa, S. S. (2011). Caregiving and Stress: Experience of People Taking Care of Elderly Relations in South-eastern Nigeria. Arts and Social Sciences Journal; ASSJ-29, 1-9.

Casale, M., Cluver, L., Crankshaw, T., Kuo, C., Lachman, J. M. and Wild, L. G. (2015). Direct and Indirect Effects of Caregiver Social Support on Adolescent Psychological Outcomes in Two South African AIDS-Affected Communities. American Journal of Community Psychology, 55, 336-346.

Al-Gamal, E., \& Long, T. (2013). Psychological distress and perceived support among Jordanian parents living with a child with cerebral palsy: A cross-sectional study. Scandinavian Journal of Caring Sciences, 27(3), 624631.

Smith, L., Hill, N., \& Kocanovik, R. (2015). Experiences of depression, the role of social support and its impact on health outcomes. Journal of mental health, 24(6), 342-346.

Kudubes, A. A., \& Bektas, M., \& Ugur, O. (2014). Symptom frequency of children with cancer and parent quality of life in Turkey. Asian Pacific Journal of Cancer Prevention, 15, 3487-3493. 